\title{
KERAGAMAN EMPAT AKSESI BUNGA MATAHARI (Helianthus annuus L.) MENGGUNAKAN PENANDA MORFOLOGI
}

\section{THE DIVERSITY OF FOUR SUNFLOWER ACCESSIONS (Helianthus annuus L.) USING MORPHOLOGICAL MARKER}

\author{
Anung Wahyudi*, Megawati Rahmasari, Nazirwan dan Miranda Ferwita Sari \\ Program Studi Teknologi Perbenihan Jurusan Budidaya Tanaman Pangan Politeknik Negeri Lampung \\ Email: anung@polinela.ac.id
}

* Corresponding Author, Diterima: 27 Sep. 2021 , Direvisi: 29 Des. 2021 , Disetujui: 21 Jan. 2022

\begin{abstract}
Sunflower (Helianthus annuus L.) is an introduced plant from eastern North America that have many uses and benefits. Sunflowers are mostly used as oil-producing plants and ornamental plants. This plant has a large genetic diversity so that it can be collected as a source of germplasm for plant breeding activities. The aim of this research was to determine the morphological diversity of four sunflower accessions. This research was carried out at the Seed Teaching farm of Politeknik Negeri Lampung from August to December 2020. This research used a single-factor randomized block design consisting of Autumn Beauty (A1), Kanigara IPB (A2), IPB BMI (A3) and Teddy Bear (A4). The observed variables included morphological characters referring to the International Board for Plant Genetic Resources (IBPGR) and the International Union for the Protection of New Varieties of Plants (UPOV). The results of this research indicate that there are differences in morphological characters in the four sunflower accessions, both in quantitative and qualitative characters. Four accessions had similarities with coefficient values between 0.48"0.58.
\end{abstract}

Keywords: Diversity, morphology, sunflower.

\section{ABSTRAK}

Bunga matahari (Helianthus annuus L.) merupakan tanaman introduksi dari Amerika Utara bagian Timur yang memiliki banyak kegunaan dan manfaat. Bunga matahari paling banyak dimanfaatkan sebagai tanaman penghasil minyak dan tanaman hias. Tanaman ini memiliki keragaman genetik yang besar sehingga dapat dikoleksi sebagai sumber plasma nutfah untuk kegiatan pemuliaan tanaman. Tujuan penelitian ini adalah untuk mengetahui keragaman morfologi empat aksesi bunga matahari. Penelitian ini dilaksanakan di lahan percobaan Seed Teaching Farm Politeknik Negeri Lampung pada bulan Agustus hingga Desember 2020. Penelitian ini menggunakan rancangan acak kelompok faktor tunggal aksesi yang terdiri dari Autumn Beauty (A1), Kanigara IPB (A2), IPB BM1 (A3) dan Teddy Bear (A4). Variabel yang diamati meliputi karakter morfologi yang mengacu pada International Board for Plant Genetic Resources (IBPGR) dan International Union For The Protection Of New Varieties Of Plant (UPOV). Hasil penelitian menunjukkan bahwa ada perbedaan karakter morfologi pada keempat aksesi bunga matahari baik pada karakter kuantitatif maupun pada karakter kualitatif. Keempat aksesi memiliki kemiripan dengan nilai koefisien antara 0,48"0,58.

Kata kunci: Bunga matahari, keragaman, morfologi.

\section{PENDAHULUAN}

Bunga matahari (Helianthus annuus L.) merupakan salah satu tanaman yang berasal dari Amerika Utara bagian Timur (Smith, 2014). Bunga matahari memiliki banyak manfaat dalam bidang pangan, industri, kesehatan dan kosmetika (Farida, 2019), salah satunya penghasil minyak di banyak
Negara. Benih-benih bunga matahari sudah banyak tersebar baik untuk produksi tanaman hias maupun untuk produksi minyak (Vega et al., 2009).

Tanaman bunga matahari memiliki variasi genetik yang cukup besar (Kaya et al., 2004). Sumber daya genetik tanaman merupakan fondasi biologi untuk memelihara dan meningkatkan kualitas tanaman (Kantar et al., 2015). Variasi genetik 
diperlukan untuk keberhasilan program pemuliaan (Komel and Razzaq, 2019). Program pemuliaan tanaman bunga matahari sebagai tanaman hias atau tanaman penghasil minyak membutuhkan koleksi plasma nutfah, lalu dilakukan kegiatan karakterisasi. Kegiatan karakterisasi menjadi salah satu tahapan yang sangat penting dalam pemuliaan tanaman bunga (Syukur et al., 2012).

Klasifikasi plasma nutfah berdasarkan karakter agronomi memainkan peran penting dalam pemuliaan tanaman untuk memilih sumber daya genetik yang berharga yang akan digunakan dalam program pemuliaan (Singh et al., 2019). Karakterisasi morfologi adalah langkah penting untuk pemanfaatan plasma nutfah secara efektif (Santos et al., 2012). Morfologi bunga dapat digunakan sebagai karakter penanda untuk mengidentifikasi hubungan genetik dalam satu genus (Sari and Purwantoro, 2018). Karakterisasi merupakan penyusunan deskripsi varietas yang menjelaskan tentang asal usul ataupun silsilah, prosedur pemuliaan, ciri-ciri morfologi, dan sifatsifat penting lainnya dari plasma nutfah yang dikoleksi (Herwati et al., 2011). Di Indonesia terdapat beberapa akesi bunga matahari yang sudah dimanfaatkan, akan tetapi untuk karakter morfologinya belum diamati secara spesifik sesuai deskriptor. Tujuan penelitian ini adalah untuk mengetahui keragaman morfologi empat aksesi bunga matahari.

\section{BAHAN DAN METODE}

\subsection{Tempat dan waktu}

Penelitian dilaksanakan di lahan percobaan Seed Teaching Farm Politeknik Negeri Lampung. Penelitian dilakukan pada bulan Agustus hingga Desember 2020.

\subsection{Bahan dan Alat Penelitian}

Bahan-bahan yang digunakan dalam penelitian ini antara lain empat aksesi bunga matahari (Autumn Beauty (A1), Kanigara IPB (A2), IPB BM1 (A3) dan Teddy Bear (A4)), tanah, pupuk kandang, sekam, insektisida, ppuk NPK. Alat-alat yang digunakan dalam penelitian ini antara lain bak perkecambahan, polybag, gembor, penggaris, meteran, jangka sorong, label dan alat tulis.

\subsection{Metode Penelitian}

Penelitian ini menggunakan rancangan acak kelompok (RAK) faktor tunggal aksesi yang terdiri dari Autumn Beauty (A1), Kanigara IPB (A2), IPB BM1 (A3) dan Teddy Bear (A4) dengan masingmasing empat ulangan, dan setiap ulangan terdapat empat sampel tanaman, sehingga didapatkan 64 satuan percobaan. Selanjutnya data dianalisis dengan analisis varian (ANOVA) taraf 5\% dengan uji lanjut Beda Nyata Jujur (BNJ) taraf 5\%.

Penelitian dilaksanakan melalui beberapa tahapan yaitu: persiapan, persemaian, pindah tanam ke polybag dengan menggunakan isolasi jarak 50 $\mathrm{m}$ antaraksesi, pemeliharaan tanaman, panen dan pascapanen. Variabel yang diamati meliputi karakter morfologi yang mengacu pada International Board For Plant Genetic Resources (IBPGR) (Anonim $\left.^{2}, 1985\right)$ dan International Union For The Protection Of New Varieties Of Plant (UPOV) (Anonim ${ }^{1}$, 2000) pada tanaman bunga matahari sebagai panduan. Variabel pengamatan dibedakan menjadi karakter kuantitatif dan karakter kualitatif. Karakter kuantitatif yang diamati antara lain tinggi tanaman (TT), panjang daun (PD), lebar daun (LD), diameter batang (DB), umur berbunga (UB), panjang bunga pita (PBP), diameter bunga pita (DBP), diameter bunga tabung (DBT), jumlah

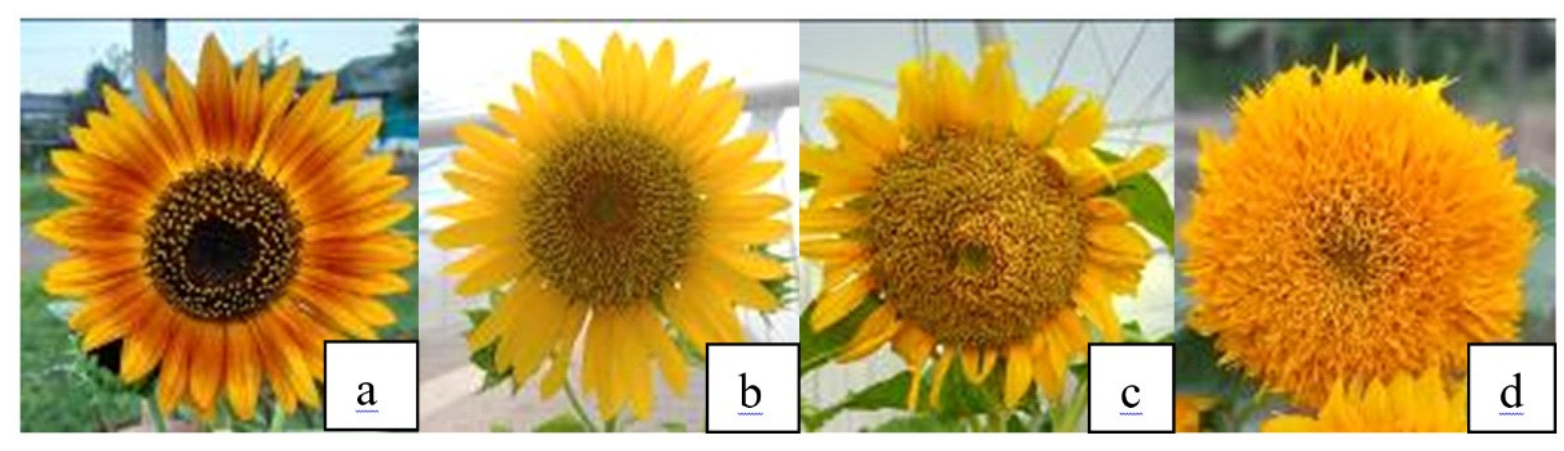

Gambar 1. Bunga matahari aksesi Autumn Beauty (a), Kanigara IPB (b), IPB BM1 (c) dan Teddy Bear (d) 
kuntum bunga (JKB), umur panen (UP), panjang biji (PB) dan lebar biji (LB), serta terdapat 21 karakter kualitatif yang diamati, di antaranya: warna daun, bentuk daun, bentuk ujung daun, bentuk pangkal daun, bentuk sayap daun, sudut vena lateral daun, tinggi ujung helai daun, bulu pada batang, bentuk ray bunga, warna bunga pita, warna bunga tabung, produksi polen, bentuk daun pelindung, tipe percabangan, sudut kepala (saat masak), bentuk permukaan bunga, bentuk biji, warna biji, garis biji, warna garis pada biji, posisi garis-garis pada biji

\section{HASIL DAN PEMBAHASAN}

Karakter morfologi utama yang digunakan sebagai penciri pada pemuliaan tanaman bunga matahari adalah bagian bunga. Beberapa karakter morfologi lebih dipengaruhi oleh lingkungan (Ciric et al., 2013), akan tetapi karakter morfologi memiliki keunggulan dalam mengidentifikasi keragaman tanaman yaitu lebih mudah dilakukan dan lebih murah. Oleh karena itu analisis keragaman dengan penanda morfologi masih banyak digunakan sampai saat ini. Hasil karakterisasi pada empat aksesi tanaman bunga matahari menunjukkan adanya keragaman pada karakter morfologi yang diamati, baik karakter kuantitatif maupun kualitatif. Karakter kuantitatif dikendalikan oleh banyak gen yang pola segregesinya tidak mengikuti hukum Mendel dan modifikasinya (Hartati et al., 2013). Empat aksesi bunga matahari yang diamati dalam penelitian ini terdiri dari Autumn Beauty (Gambar 1a), Kanigara IPB (Gambar 1b), IPB BM 1 (Gambar 1c), dan Teddy Bear (Gambar 1d).

Masing-masing aksesi memiliki fase pertumbuhan yang berbeda. Hal tersebut dapat dilihat dari pola tumbuh yang bervariasi antar aksesi, misalnya pertambahan tinggi tanaman, pertambahan jumlah daun, waktu berbunga, dan waktu panen yang beragam. Informasi waktu berbunga merupakan dasaryang penting dalam bidang pemuliaan tanaman sehingga dapat digunakan sebagai landasan untuk perakitan varietas-varietas unggul melalui hibridisasi (Jamsari et al., 2007).

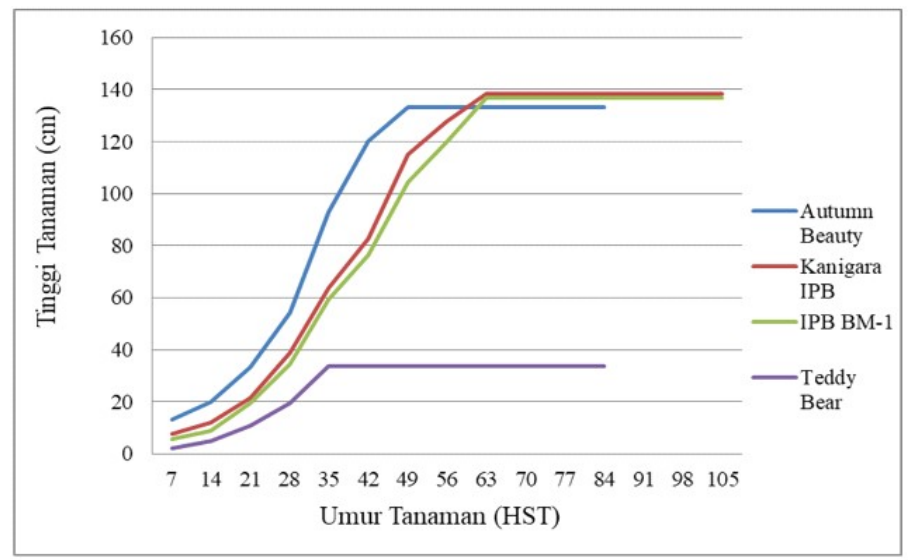

Gambar 2. Grafik Pertumbuhan Tinggi Tanaman

Tabel 1. Rekapitulasi Hasil Uji BNJ Taraf 5\% pada Karakter Kuantitatif.

\begin{tabular}{lcrrr}
\hline \multirow{2}{*}{ Karakter } & \multicolumn{4}{c}{ Aksesi } \\
\cline { 2 - 5 } & Autumn Beauty & Kanigara IPB & IPB BM1 & Teddy Bear \\
\hline Panjang daun (cm) & $20,59^{\mathrm{a}}$ & $18,63^{\mathrm{b}}$ & $19,80^{\mathrm{ab}}$ & $15,02^{\mathrm{c}}$ \\
Lebar daun (cm) & $18,22^{\mathrm{b}}$ & $16,97^{\mathrm{b}}$ & $20,87^{\mathrm{a}}$ & $11,90^{\mathrm{c}}$ \\
Diameter batang (cm) & $1,25^{\mathrm{b}}$ & $1,28^{\mathrm{b}}$ & $1,82^{\mathrm{a}}$ & $0,88^{\mathrm{c}}$ \\
Umur berbunga (hst) & $44,88^{\mathrm{c}}$ & $59,61^{\mathrm{b}}$ & $69,88^{\mathrm{a}}$ & $38,46^{\mathrm{c}}$ \\
Panjang bunga pita (cm) & $4,75^{\mathrm{a}}$ & $4,23^{\mathrm{b}}$ & $5,06^{\mathrm{a}}$ & $2,77^{\mathrm{c}}$ \\
Diameter bunga pita (cm) & $13,93^{\mathrm{b}}$ & $16,22^{\mathrm{a}}$ & $18,70^{\mathrm{a}}$ & $9,37^{\mathrm{c}}$ \\
Diameter bunga tabung (cm) & $7,17^{\mathrm{b}}$ & $9,05^{\mathrm{a}}$ & $10,18^{\mathrm{a}}$ & $0,00^{\mathrm{c}}$ \\
Jumlah kuntum bunga (helai) & $22,27^{\mathrm{a}}$ & $20,79^{\mathrm{a}}$ & $14,29^{\mathrm{b}}$ & $9,04^{\mathrm{c}}$ \\
Umur panen (hst) & $83,38^{\mathrm{b}}$ & $104,15^{\mathrm{a}}$ & $108,63^{\mathrm{a}}$ & $80,65^{\mathrm{b}}$ \\
Panjang biji (cm) & $0,67^{\mathrm{a}}$ & $0,77^{\mathrm{a}}$ & $0,42^{\mathrm{c}}$ & $0,66^{\mathrm{b}}$ \\
Lebar biji (cm) & $0,33^{\mathrm{a}}$ & $0,37^{\mathrm{a}}$ & $0,42^{\mathrm{a}}$ & $0,37^{\mathrm{a}}$ \\
\hline Keterangan & & & &
\end{tabular}

Keterangan: Angka-angka pada baris yang sama diikuti oleh huruf yang sama, tidak berbeda nyata pada uji BNJ dengan tingkat signifikansi 5\%. 
Berdasarkan hasil pengukuran tinggi tanaman (Gambar 2), diketahui bahwa pola pertumbuhan pada masing-masing aksesi beragam. Menurut Farida (2019) pola pertumbuhan tinggi tanaman dapat dikelompokkan menjadi 3 berdasarkan waktu berhentinya pertambahan tinggi. Tinggi tanaman berhenti pada pola 1 saat berumur $<91$ hst (hari setelah tanam) pola 2 saat berumur 91 "110 hst dan pola 3 saat berumur $>110$ hst. Aksesi Autumn Beauty dan Teddy Bear termasuk dalam kategori pola 1, sedangkan aksesi Kanigara IPB dan IPB BM1 termasuk dalam kategori pola 2. Aksesi yang memiliki tinggi tanaman terendah adalah aksesi Teddy Bear yang dapat dimanfaatkan sebagai tanaman hias pot karena berukuran pendek, sedangkan ketiga aksesinya lainnya dapat dimanfaatkan sebagai tanaman hias yang dapat ditanam di kebun atau sebagai tanaman pagar.

Tabel 1 menunjukkan hasil analisis pada 11 karakter kuantitatif yang diamati. Karakter panjang

Tabel 2. Sebaran Sifat Karakter Kualitatif 4 Aksesi Bunga Matahari.

\begin{tabular}{|c|c|c|}
\hline Variabel & Sebaran Sifat Karakter Kualitatif & Aksesi \\
\hline \multirow{2}{*}{ Warna daun } & light green (hijau muda) (1 var) & A4 \\
\hline & medium green (hijau sedang) (3 var) & $\mathrm{A} 1, \mathrm{~A} 2$ dan $\mathrm{A} 3$ \\
\hline \multirow[t]{2}{*}{ Bentuk daun } & triangular (segitiga) (1 var) & $\mathrm{A} 3$ \\
\hline & cordate (berbentuk hati) (3 var) & $\mathrm{A} 1, \mathrm{~A} 2$ dan $\mathrm{A} 4$ \\
\hline \multirow[t]{2}{*}{ Bentuk ujung daun } & broad triangular (segitiga lebar) (2 var) & A1 dan A2 \\
\hline & acuminate (tajam) (2 var) & A3 dan A4 \\
\hline Bentuk pangkal daun & auriculate (bertelinga) (4 var) & $\mathrm{A} 1, \mathrm{~A} 2, \mathrm{~A} 3$ dan $\mathrm{A} 4$ \\
\hline \multirow[t]{2}{*}{ Bentuk sayap daun } & weakly expressed (diekspresikan dengan lemah) (1 var) & A3 \\
\hline & strongly expressed (diekspresikan dengan kuat) (3 var) & $\mathrm{A} 1, \mathrm{~A} 2$ dan $\mathrm{A} 4$ \\
\hline \multirow[t]{2}{*}{ Sudut vena lateral daun } & acute (tajam) (3 var) & $\mathrm{A} 1, \mathrm{~A} 2$ dan $\mathrm{A} 3$ \\
\hline & $\begin{array}{l}\text { right angle or nearly right angle (sudut siku-siku atau sudut hampir } \\
\text { siku-siku) (1 var) }\end{array}$ & A4 \\
\hline \multirow{2}{*}{ Tinggi ujung helai daun } & medium (sedang) (3 var) & $\mathrm{A} 1, \mathrm{~A} 2$ dan $\mathrm{A} 4$ \\
\hline & high (tinggi) (1 var) & A3 \\
\hline \multirow[t]{2}{*}{ Bulu pada batang } & medium (sedang) (2 var) & A2 dan A4 \\
\hline & strong (kuat) (2 var) & A1 dan A3 \\
\hline \multirow[t]{3}{*}{ Bentuk ray bunga } & narrow ovate (bulat telur sempit) (2 var) & A2 dan A3 \\
\hline & broad ovate (bulat telur lebar) (1 var) & A1 \\
\hline & rounded (bulat) (1 var) & A4 \\
\hline \multirow{3}{*}{ Warna bunga pita } & yellow (kuning) (2 var) & $\mathrm{A} 2$ dan $\mathrm{A} 3$ \\
\hline & orange (oranye) (1 var) & A4 \\
\hline & multicolor (warna-warni) (1 var) & A1 \\
\hline \multirow{3}{*}{ Warna bunga tabung } & absent (tidak hadir) (1 var) & A4 \\
\hline & yellow (kuning) (2 var) & $\mathrm{A} 2$ dan $\mathrm{A} 3$ \\
\hline & purple (ungu) (1 var) & A1 \\
\hline Produksi polen & present (hadir) (4 var) & $\mathrm{A} 1, \mathrm{~A} 2, \mathrm{~A} 3$ dan $\mathrm{A} 4$ \\
\hline \multirow[t]{2}{*}{$\begin{array}{l}\text { Bentuk daun pelindung } \\
\text { (kelopak bunga) }\end{array}$} & $\begin{array}{l}\text { convergent or triangular (konvergen atau segitiga) } \\
\text { ( } 2 \text { var) }\end{array}$ & A1 dan A3 \\
\hline & rounded (bulat) (2 var) & $\mathrm{A} 2$ dan $\mathrm{A} 4$ \\
\hline \multirow[t]{2}{*}{ Tipe percabangan } & top branching (percabangan atas) (2 var) & $\mathrm{A} 2$ dan $\mathrm{A} 3$ \\
\hline & $\begin{array}{l}\text { fully branched with central head (percabangan penuh dengan kepala } \\
\text { di tengah) ( } 2 \text { var) }\end{array}$ & A1 dan A4 \\
\hline \multirow{3}{*}{$\begin{array}{l}\text { Sudut kepala (saat } \\
\text { masak) }\end{array}$} & $90^{\circ}(2$ var $)$ & A3 dan A4 \\
\hline & $135^{\circ}$ (1 var) & A1 \\
\hline & $180^{\circ}$ (1 var) & $\mathrm{A} 2$ \\
\hline Bentuk permukaan & concave (cekung) (3 var) & $\mathrm{A} 1, \mathrm{~A} 2$ dan $\mathrm{A} 3$ \\
\hline bunga & flat (datar) (1 var) & A4 \\
\hline \multirow[t]{3}{*}{ Bentuk biji } & $\begin{array}{l}\text { ovoid elongated (berbentuk telur bulat memanjang) } \\
\text { (1 var) }\end{array}$ & A3 \\
\hline & ovoid wide (berbentuk telur bulat lebar) (1 var) & A4 \\
\hline & rounded (bulat) (2 var) & A1 dan $\mathrm{A} 3$ \\
\hline \multirow[t]{2}{*}{ Warna biji } & brown (coklat) (1 vari) & A1 \\
\hline & black (hitam) (3 var) & $\mathrm{A} 2, \mathrm{~A} 3$ dan $\mathrm{A} 4$ \\
\hline Garis biji & absent (tidak hadir) (3 var) & $\mathrm{A} 1, \mathrm{~A} 2$ dan $\mathrm{A} 4$ \\
\hline Warna garis pada biji & absent (tidak hadir) (3 var) & $\mathrm{A} 1, \mathrm{~A} 2$ dan A4 \\
\hline Posisi garis-garis pada & $\begin{array}{l}\text { white (putih) ( } 1 \text { var) } \\
\text { absent (tidak hadir) (3 var) }\end{array}$ & $\begin{array}{l}\mathrm{A} 3 \\
\mathrm{~A} 1, \mathrm{~A} 2 \text { dan } \mathrm{A} 4\end{array}$ \\
\hline biji & both marginal and lateral (keduanya marjinal dan lateral) (1 var) & $\mathrm{A} 3$ \\
\hline
\end{tabular}

Keterangan: A1 (Autumn Beauty), A2 (Kanigara IPB), A3 (IPB BM1), A4 (Teddy Bear). 
daun, lebar daun, diameter batang, umur berbunga, panjang bunga pita, diameter bunga pita, diameter bunga tabung, jumlah kuntum bunga, umur panen, panjang biji menunjukkan adanya perbedaan antaraksesi, sedangkan lebar biji tidak berpengaruh nyata. Aksesi Autumn Beauty memiliki panjang daun dan jumlah kuntum yang lebih banyak dibandingkan aksesi lainnya. Aksesi Kanigara IPB memiliki panjang biji dan lebar biji yang lebih besar dibandingkan aksesi lainnya. Aksesi IPB BM1 memiliki luas daun, diameter batang, panjang bunga pita dan diameter bunga pita yang lebih baik dibandingkan aksesi lainnya, serta umur berbunga, dan umur umur panen yang lebih baik dibandingkan aksesi lainnya. Aksesi Teddy Bear memiliki nilai yang rendah pada karakter panjang daun, luas daun, diameter batang, panjang bunga pita dan diameter bunga pita, jumlah kuntum bunga dan umur panen. Aksesi bunga matahari yang diamati memiliki keragaman untuk 11 karakter kuantitatif yang diamati.

Pengamatan karakter kualitatif mulai dilakukan pada fase vegetatif hingga pasca panen. Terdapat 21 variabel yang diamati meliputi karakter yang mengacu pada International Board For Plant Genetic Resources (IBPGR) (Anonim² ${ }^{2}$ 1985) dan International Union For The Protection Of New Varieties Of Plant (UPOV) (Anonim ${ }^{1}, 2000$ ) untuk tanaman bunga matahari sebagai panduan. Pengamatan pada karakter kualitatif juga terdapat keragaman dari keempat aksesi yang diamati (Tabel 2).

Karakter kualitatif merupakan karakter yang dikendalikan oleh gen sederhana (satu ataupun dua gen) dan tidak atau sedikit sekali dipengaruhi oleh lingkungan (Syukur et al., 2012). Berdasarkan hasil karakter kualitatif pada empat aksesi bunga matahari yang telah diamati menunjukan adanya keragaman, kecuali pada bentuk pangkal daun dan produksi polen (Tabel 2). Menurut Mangoendidjojo (2003) apabila terdapat perbedaan pada populasi tanaman yang ditanam pada kondisi lingkungan yang sama maka perbedaan tersebut disebabkan oleh perbedaan yang berasal dari genotip populasi yang ditanam.

Dendogram kemiripan keempat aksesi bunga matahari didapatkan dari hasil analisis semua karakter morfologi yang diamati. Berdasarkan dendogram seperti yang terlihat pada Gambar 2, keempat aksesi terbagi menjadi 2 kelompok besar dengan koefisien kemiripan 0,48. Kelompok A terdiri dari aksesi Autumn Beauty, Kanigara IPB dan IPB BM1, sedangkan aksesi Teddy Bear ada pada kelompok B. Aksesi Autumn Beauty memiliki kemiripan dengan aksesi Kanigara IPB dengan nilai koefisien 0,58 dan kedua aksesi tersebut memiliki kemiripan dengan aksesi IPB BM1 dengan koefisien 0,485. Koefisien kemiripan keempat aksesi jauh dari nilai 1 yang artinya keempat aksesi tersebut memiliki keragaman yang tinggi.

Sifat-sifat morfologi dari empat aksesi bunga matahari yang diamati memperlihatkan adanya keragaman. Keragaman suatu karakter yang diamati dapat menjadi informasi yang penting dalam proses pemuliaan tanaman. Modal dasar pemuliaan tanaman adalah adanya keragaman yang luas, sehingga proses seleksi dapat dilakukan secara efektif. Keragaman yang luas dapat memberikan peluang yang lebih besar untuk mendapatkan karakter-karakter yang diinginkan (Widiastuti et al., 2013).

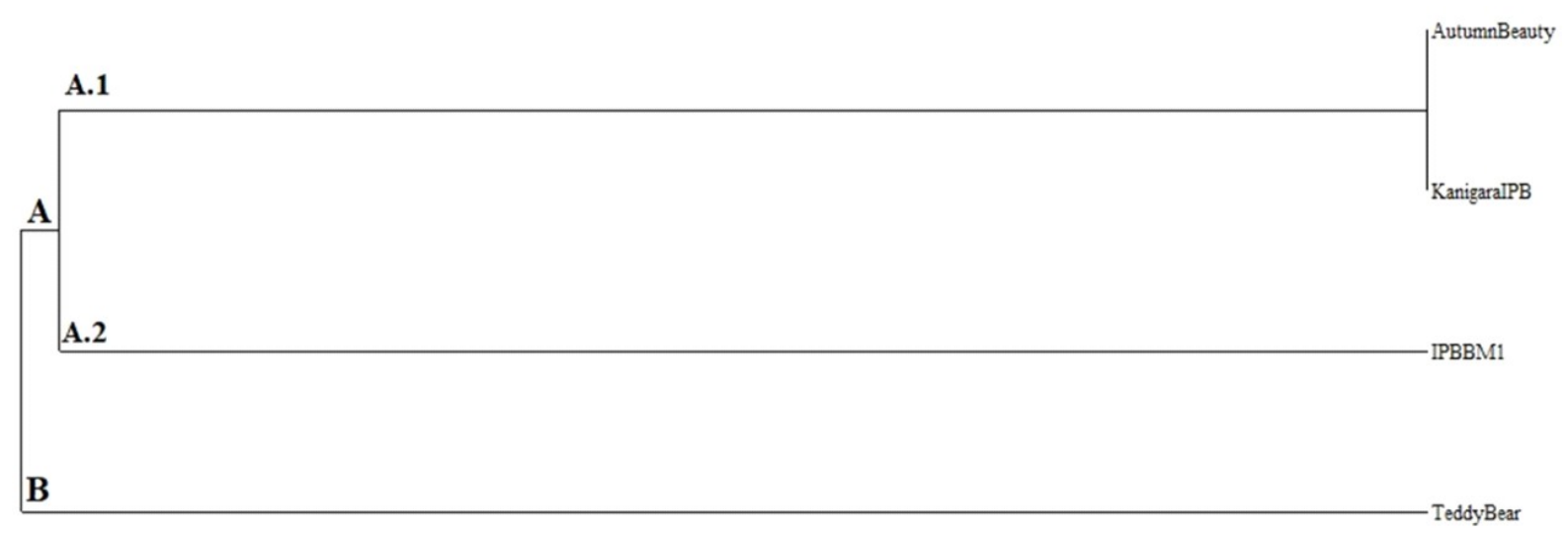

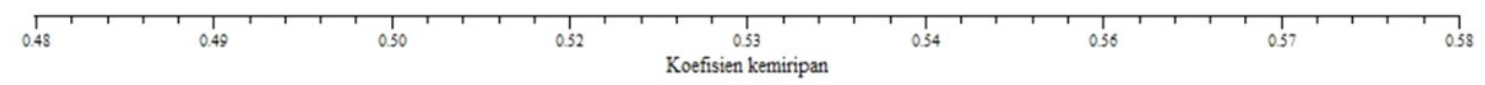

Gambar 2. Dendogram Kemiripan Empat Aksesi Bunga Matahari 
Berdasarkan karakter morfologi yang telah diamati, terdapat potensi empat aksesi tanaman bunga matahari untuk diproduksi sebagai tanaman hias (ornamental). Pengembangan bunga matahari yang berpotensi sebagai tanaman hias difokuskan pada warna bunga, durasi pembungaan, dan karakteristik morfologi lainnya yang sebagian besar berkaitan dengan efek visual tanaman (Mladenoviæ et al., 2016). Menurut Hazmy et al. (2017) yang berpotensi sebagai tanaman hias ditentukan berdasarkan karakter tinggi tanaman. Aksesi Teddy Bear memiliki postur yang pendek, sehingga akan sangat cocok digunakan sebagai tanaman hias pot, ditambah dengan bunga yang dihasilkan berbentuk double pompon berwarna orange akan lebih menarik dan menjadi nilai tambah. Tanaman bunga matahari yang memiliki tinggi kurang dari $130 \mathrm{~cm}$ berpotensi sebagai tanaman hias. Aksesi Autumn Beauty, Kanigara IPB dan IPB BM1 memiliki postur yang tinggi dengan ukuran bunga yang dihasilkan relatif besar, warna bunga yang beragam dan sangat menarik terutama Autumn Beauty yang warna bunganya berbeda dengan warna bunga yang dihasilkan bunga matahari pada umumnya. Ketiga aksesi tersebut lebih berpotensi jika digunakan untuk tujuan bunga potong, tanaman hias di kebun atau sebagai tanaman pagar.

\section{KESIMPULAN}

Aksesi Autumn Beauty, Kanigara IPB, IPB BM1 dan Teddy Bear memiliki kemiripan dengan nilai koefisien antara $0,48 " 0,58$. Keempat aksesi memiliki keragaman morfologi pada banyak karakter antara lain tinggi tanaman, jumlah daun, panjang daun, lebar daun, diameter batang, umur berbunga, panjang bunga pita, diameter bunga pita, diameter bunga tabung, jumlah kuntum bunga, umur panen dan panjang biji yang berbeda. Pada karakter kualitatif, keempat aksesi memiliki karakter yang sama pada karakter bentuk pangkal daun dan produksi polen, sedangkan untuk karakter lainnya relatif berbeda.

\section{DAFTAR PUSTAKA}

Anonim $^{1}$, 2000. Sunflower (Helianthus annuus L.). International Union for The Protection of New Varieties Of Plant (UPOV), Geneva. $31 \mathrm{hlm}$.

Anonim $^{2}$, 1985. Sunflower Descriptors. International Board for Plant Genetic Resources (IBPGR), Rome. $33 \mathrm{hlm}$.
Ciric, M., S. Jocic, S. Cvejic, M. Jockovic, P. Canak, R. Marinkovic, and M. Ivanovic. 2013. Combining abilities of new inbred lines of sunflower (Helianthus annuus L.). Genetika. 45(2):289-296.

Farida, D.G. 2019. Fenologi dan karakterisasi morfo-agronomi tanaman bunga matahari (Helianthus annuus L.) pada kawasan tropis. Jurnal Produksi Tanaman. 7(5):792-800.

Hartati, S., M. Barmawi, dan N. Sa'diyah. 2013. Pola segregasi karakter agronomi tanaman kedelai (Glycine max [L.] Merrill) generasi $\mathrm{F}_{2}$ hasil persilangan Wilis x B3570. J. Agrotek Tropika. 1(1):8-13.

Hazmy, Z.D., Ainnurrasjid, dan Damanhuri. 2017. Rejuvenasi dan karakterisasi morfologi plasma nutfah bunga matahari (Helianthus annuus L.). Jurnal Produksi Tanaman. 5(7):1133-1142.

Herwati, A., R.D. Purwati, T.D.A. Anggraeni. 2011. Penampilan karakter kualitatif pada plasma nutfah tanaman bunga-matahari. Prosiding Seminar Nasional Inovasi Perkebunan. Balai Penelitian Tanaman Tembakau dan Serat.

Jamsari, Yaswendri, M. Kasim. 2007. Phenology of flower and fruit development in Uncaria gambir Species. Biodiversitas. 8(2):141-146.

Kantar, M.B., C.C. Sosa, C.K. Khoury, N.P. Castañeda-Álvarez, H.A. Achicanoy, V. Bernau, N.C. Kane, L. Marek, G. Seiler, and L.H. Rieseberg. 2015. Ecogeography and utility to plant breeding of the crop wild relatives of sunflower (Helianthus annuus L.). Frontiers in Plant Science. 6 : 1-11.

Kaya, Y., D. Baltensperger, L. Nelson, and J. Miller. 2004. Maturity grouping in sunflower (Helianthus annuus L.) Helia. 27 (40) : 257-270.

Mangoendidjojo, W., 2003. Dasar-Dasar Pemuliaan Tanaman. Kanisius, Yogyakarta. $182 \mathrm{hlm}$.

Mladenoviæ, E., S. Cvejic., J. Cukanovic., G. Zeravica and S. Josic. 2016. Evaluation of sunflower genotypes for ornamental use. Contemporary Agriculture 65:39-43.

Santos, R.C., J.L. Pires, and R.X. Correa. 2012. Morphological characterization of leaf, flower, fruit and seed traits among Brazilian Theobroma L. species. Genet Resour Crop Evol. 59: 327-345.

Sari, M.F., dan A. Purwantoro. 2018. Diversity analysis of 15 hibiscus accession based on 
RAPD marker. Ilmu Pertanian (Agricultural Science). 3(2):90-95.

Komel,S., and A. Razzaq. 2019. Association among Morphological and Yield Related Traits in Different Accessions of Sunflower (Helianthus annuus L.). Russ. Agricult. Sci. 45(2):128-136.

Singh, V.K., R.K. Sheoran, S. Chander, and B. Sharma. 2019. Genetic variability, evaluation and characterization of sunflower (Helianthus annuus L.) germplasm. Bangladesh J. Bot. 48(2):253-263.

Smith, B.D., 2014. The domestication of Helianthus annuus L. (sunflower). Veget Hist Archaeobot. 23:57-74.
Syukur, M., S. Sujiprihati, dan R. Yunianti. 2012. Teknik Pemuliaan Tanaman. Penebar Swadaya, Jakarta. $348 \mathrm{hlm}$.

Vega, T., G. Breccia, G. Nestares, M.L. Mayor, R. Zorzoli, and L. Picardi. 2009. Soil-less bioassays for early screening for resistance to imazapyr in sunflower (Helianthus annuus L.). Pest. Manag. Sci. 65:991-995.

Widiastuti, A., Sobir, dan M.R. Suhartanto. 2013. Analisis keragaman manggis (Garcinia mangostana) diiradiasi dengan sinar gamma berdasarkan penanda ISSR. Bioteknologi. 10(1):15-22. 